\title{
Viability Analysis of Waste Tires as Material for Rail Vibration and Noise Control in Modern Tram Track Systems
}

\author{
Caiyou Zhao,, ${ }^{1,2}$ Ping Wang, ${ }^{1,2}$ Qiang Yi, ${ }^{1,2}$ and Duo Meng ${ }^{1,2}$ \\ ${ }^{1}$ Key Laboratory of High-Speed Railway Engineering, Ministry of Education, Southwest Jiaotong University, Chengdu 610031, China \\ ${ }^{2}$ School of Civil Engineering, Southwest Jiaotong University, Chengdu 610031, China \\ Correspondence should be addressed to Ping Wang; 381657901@qq.com
}

Received 19 December 2014; Revised 3 February 2015; Accepted 16 February 2015

Academic Editor: Jeong-Hoi Koo

Copyright (c) 2015 Caiyou Zhao et al. This is an open access article distributed under the Creative Commons Attribution License, which permits unrestricted use, distribution, and reproduction in any medium, provided the original work is properly cited.

\begin{abstract}
This research study focused on the effect of using damping chamber elements made from waste tires on railway noise reduction. First, the energy absorption characteristics of damping chamber elements with various gradation combinations and compaction indices were measured in the laboratory using compression testing. The laboratory compression results demonstrated that the optimal gradation combination of damping chamber elements is as follows: the content of fine rubber particles is $10 \%$, the content of coarse granules is $90 \%$, and the optimal compaction index is 0.98 . Next, the findings from the laboratory compression-test studies were used to produce damping chamber elements that were applied to a full-scale modern track model in the laboratory. The measurements of the dynamic properties indicated that the damping chamber elements could significantly reduce the vibration levels of the rail head. Finally, the damping chamber elements, which had been proven effective through laboratory dynamic tests, were widely applied to test rail sections in the field. The field tests demonstrated that damping chamber elements can significantly increase the track vibration decay rate in the frequency range of $200-10000 \mathrm{~Hz}$. Therefore, damping chamber elements made from waste tires are able to control rail vibration and noise in modern tram track systems.
\end{abstract}

\section{Introduction}

In recent decades, due to accelerated industrialization and urbanization and the enhancement of human living standards, the number of private vehicles has significantly increased, which causes increasingly serious traffic congestion in cities and leads to air pollution caused by automobile exhaust, as exemplified by the "haze" phenomenon [1]. In contrast, new modern tram facilities, which have a variety of advantages over private vehicles, such as their high load capacity, energy efficiency, and environmental friendliness, have been demonstrated to help relieve congestion within cities; in addition, the perceptions of cities are improved through the use of clean-running public transport [2]. Although often viewed as a resource-conserving and environmentally friendly means of transportation, trams introduce a new component to the urban noise scene. Complaints from residents living along rail lines indicate that these trams may lead to annoyance and may be perceived as a nuisance.
Theoretical and empirical models have been developed to understand and predict the noise from trams, and these models have been validated in extensive field measurements [3-5]. The predominant source of environmental noise from tram systems is rolling noise. The roughness of the running surfaces generates excitation that causes vibration of the wheel and track. Both the wheels and the track radiate significant noise components, whose relative amplitudes depend on the details of the design, the roughness spectrum, and the train speed. The noise component from the rail is often greatest at the lower running speeds of typical tram rail systems.

The main parameter with the strongest influence on the amount of noise radiated by the rail is the rate of decay of vibration in the vertical direction along the rail, usually expressed in $\mathrm{dB} / \mathrm{m}[6]$. In general, two approaches are used to increase the decay rate of the rail: one approach is to increase the rail pad stiffness and the other approach is to add damping elements to the rail. Increasing the rail 


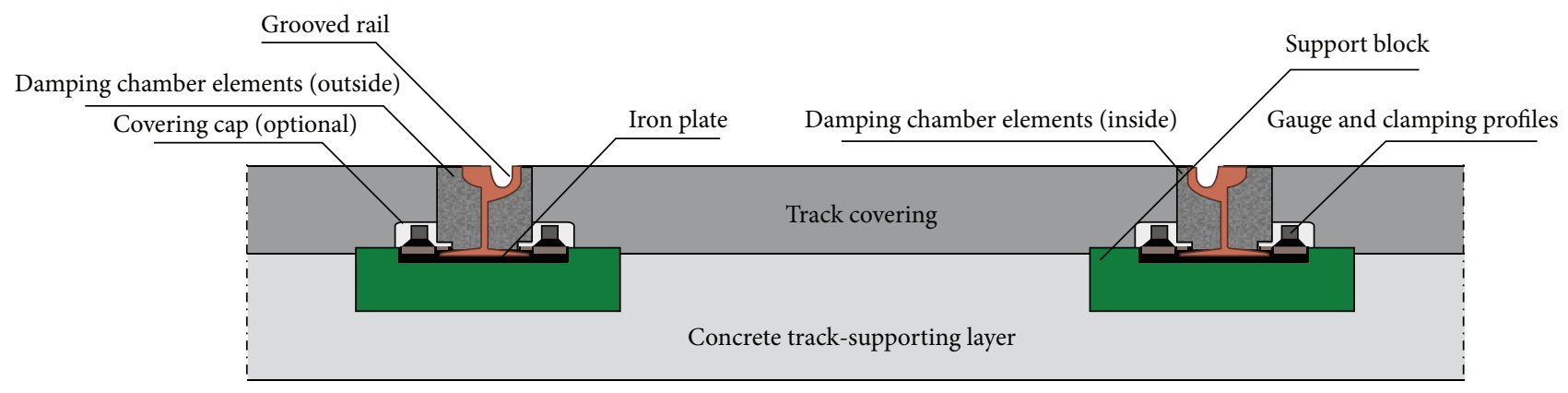

FIGURE 1: Cross section of the modern tram track system.

pad stiffness could increase the decay rate of the rail on the one hand but leads to larger track forces and higher vibration transmitted to the environment on the other hand. Therefore, in practical applications, soft pads have become commonly applied to reduce track deterioration and groundborne vibrations. As a result, the second approach has drawn much attention and has been proven to be an effective means of increasing rail decay rate and, thus, decreasing the rail noise. The most important methods for application of this approach to the rails of conventional track systems are the use of two-layer tuned absorber systems [7], rail dampers [8], double-tuned rail dampers [9], and constrained layer dampers [10]. For modern tram systems, one of the most efficient solutions to overcome the "noise and vibration problem" is the use of a silent "embedded" track, as shown in Figure 1, which has been used in China. The structure of the silent embedded track consists of a concrete track-supporting layer, two support blocks, and a track covering into which the rails are embedded by means of damping chamber elements made of viscoelastic damping materials. Due to their unique structural properties of gentle energy absorption and high damping, these chamber elements can dramatically increase the rail damping, thereby increasing the decay rate of the rail.

Damping chamber elements are commonly manufactured using porous damping elastomer materials, such as butyl rubber, polyacrylic ester, acrylonitrile-butadiene rubber, epoxy resin, and ethylene-vinyl acetate copolymer blends. However, the use of elastic damping waste materials to produce these elements has the added advantage of reducing the consumption of raw materials and of revalorizing a waste material that is otherwise difficult to eliminate. For this reason, waste tires, which have been used in diverse applications in civil engineering $[11,12]$, are used to fabricate the damping chamber elements to reduce noise from trams. This application of waste tires, which is completely different from their previous applications, requires outstanding mechanical properties, strong energy absorption capacity, and excellent vibration reduction capacity.

With the aim of meeting these requirements, an innovative technological process was developed. In this method, the waste rubber was first ground into particles; next, these particles were screened and activated, after which the activated particles were mixed with polyurethane and carbon black; finally, the mixture was vulcanized. In this context, the present study focuses on the development of damping chamber elements from waste tires and the analysis of their viability for use as damping elements in modern tram tracks. The research consisted of the following three stages: (i) selection of the most appropriate design parameters of waste-tires damping chamber elements (WTDCEs) for use in modern tram tracks; (ii) determination of the vibration damping effect of WTDCEs, evaluating their attenuation of the rail-head accelerance in modern tram tracks through a full-scale test in the laboratory; (iii) comparative analysis of the actual damping effect of WTDCEs on the vibration decay rate of tracks based on a field experiment.

\section{Methodology}

2.1. Characteristics of the Materials. For this investigation, the damping chamber elements were manufactured from three raw materials: rubber granules, carbon black, and polyurethane. Rubber granules, as the predominant material, were obtained from waste automobile tires, whose main material is rubber with the appropriate mechanical characteristics for use in engineering applications. These granules were obtained by a progressive technological process that consists of grinding up the waste rubber into particles, screening the chopped tire particles, and then activating the screened particles innovatively. In comparison with other techniques, this deconstruction process provides high value materials because only granules possessing excellent mechanical properties are retained, and those retained granules are further activated. In this study, these deconstructed waste-tires particles are of two main size grades, $4-5 \mathrm{~mm}$ and $1-3 \mathrm{~mm}$, as shown in Figures 2(a) and 2(b), respectively, and they are used to make damping chamber elements. The main characteristics of the tire layers used in this work are presented in Table 1.

In addition, two accessory materials, carbon black (N330) and polyurethane, as shown in Figures 2(c) and 2(d), respectively, are added to improve and enhance the physical and mechanical properties of the damping chamber elements and to mix the activated rubbers granulates together. The main physical and mechanical properties of the polyurethane used in this work are presented in Table 2.

2.2. Process and Proportions of the Mixes. According to previous investigations, the mechanical properties and energy absorption capacity of porous damping elastomer are related to the composition and microstructure of the cell wall 


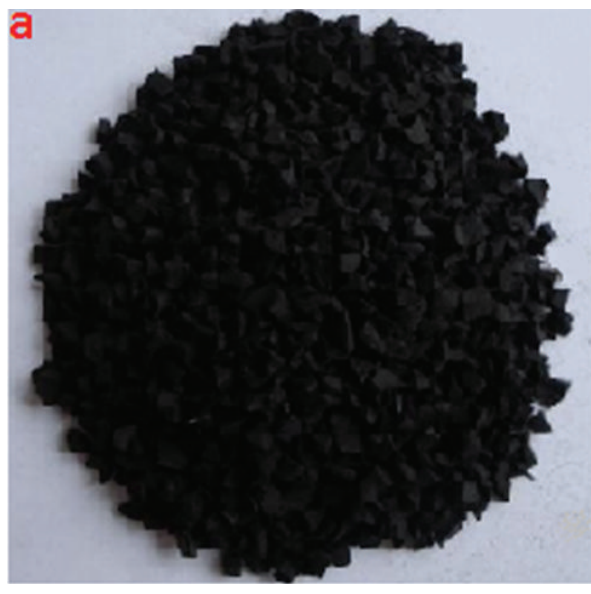

(a)

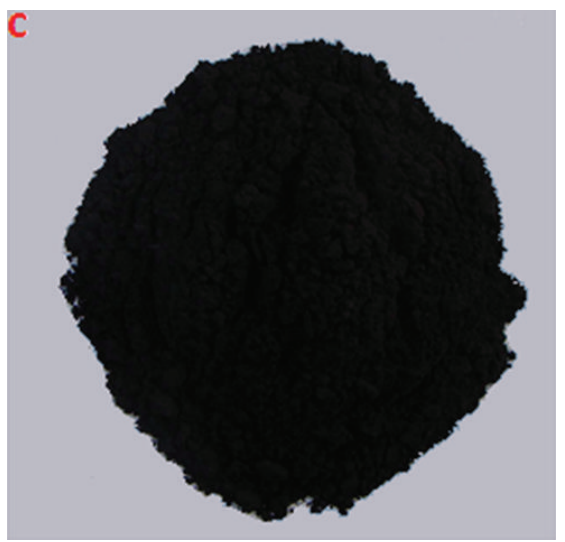

(c)

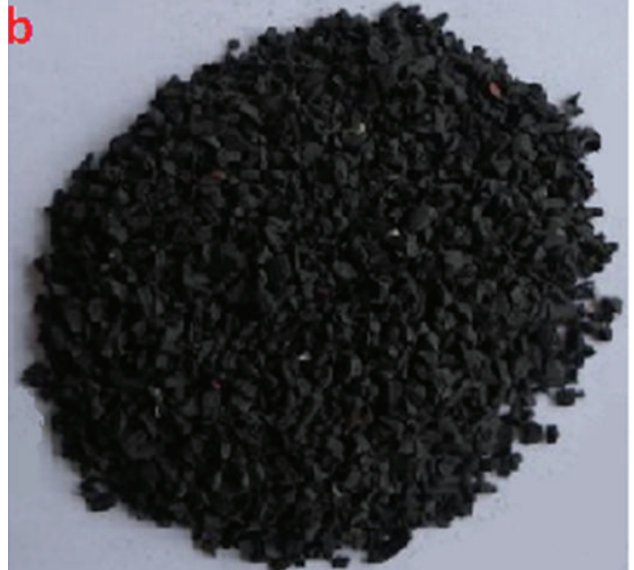

(b)

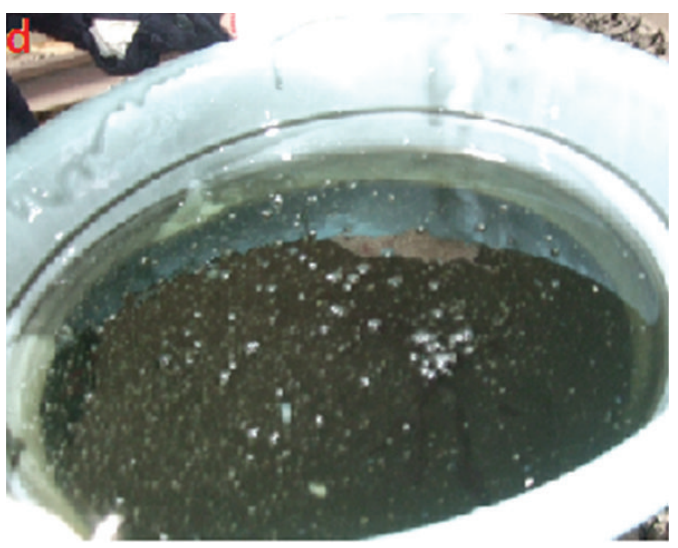

(d)

FIGURE 2: Main materials of the damping chamber elements: deconstructed waste-tires particle of 4-5 mm (a) and 1-3 mm (b), carbon black (c), and polyurethane (d).

TABLE 1: Main physical and mechanical properties of the waste tires.

\begin{tabular}{lc}
\hline Properties & Tire \\
\hline Shore hardness $\left({ }^{\circ}\right)$, ISO 868 & $65-70$ \\
Density $\left(\mathrm{g} / \mathrm{cm}^{3}\right)$, ISO 1183 & $1.05-1.20$ \\
Transverse tensile strength, ISO $37(\mathrm{MPa})$ & $10-12$ \\
Minimum transverse elongation, ISO 37 $(\%)$ & $136-142$ \\
\hline
\end{tabular}

rubber particles. For a given design, addition amount, and application method of a particular accessory material, the composition and microstructure are dependent on the gradation combination of the rubber particles and the compaction index of the chamber elements. Hence, the gradation combination and the compaction index are important factors when designing porous damping elastomer elements. The mix proportions used in this study to examine the effect of the design parameters are listed in Table 3 . Each mix proportion is designated by a specific code. "SC" and "SGC" represent the same compaction index and the same gradation combination, respectively. The second labels, "10," “30," "50," “70," and "90," denote the amount of rubber particles ( terms of their weight percentage. The third labels, "1.1," "1.2,"
TABLE 2: Physical and mechanical properties of polyurethane.

\begin{tabular}{lc}
\hline Properties & Polyurethane \\
\hline Density $\left(\mathrm{g} / \mathrm{cm}^{3}\right)$, ISO 1183 & 1.00 \\
Shore hardness $\left({ }^{\circ}\right)$, ISO 868 & 90 \\
Bond strength (MPa), ISO-10364-1993 & 3 \\
Tensile strength (MPa), ISO 37-2005 & 10 \\
Breaking elongation (\%), ISO 37-2005 & 250 \\
Low-temperature brittleness ( $\left.{ }^{\circ} \mathrm{C}\right)$, ISO 812-1991 & -50 \\
Compression strength (MPa), ISO 604-2002 & 30 \\
\hline
\end{tabular}

"1.3," "1.4," and "1.5," refer to the compaction indices of the specimens used.

Once the optimal properties of the WTDCEs were determined for use in a modern tram track system, 10 specimens were used to analyze the durability of the material and 4 specimens were used to evaluate the effect of the use of WTDCEs on the mechanical response of the railway track. In addition, for this latter study, the optimal damping chamber elements were produced and applied in a laboratory test section. The vibration decay rates of track in the vertical direction along the rail with and without the WTDCEs were measured and compared according to [13]. 
TABLE 3: Mix proportion.

\begin{tabular}{|c|c|c|c|c|}
\hline Specimen & Rubber particles of $1-3 \mathrm{~mm}$ (vol. \%) & Rubber particles of 4-5 mm (vol. \%) & Compaction index & Density \\
\hline SC-10-1.1 & $10 \%$ & $90 \%$ & 0.88 & 1.017 \\
\hline SC-30-1.1 & $30 \%$ & $70 \%$ & 0.88 & 1.017 \\
\hline SC-50-1.1 & $50 \%$ & $50 \%$ & 0.88 & 1.017 \\
\hline SC-70-1.1 & $70 \%$ & $30 \%$ & 0.88 & 1.017 \\
\hline SC-90-1.1 & $90 \%$ & $10 \%$ & 0.88 & 1.017 \\
\hline SGC-10-0.88 & $10 \%$ & $90 \%$ & 0.88 & 1.017 \\
\hline SGC-10-0.92 & $10 \%$ & $90 \%$ & 0.92 & 1.056 \\
\hline SGC-10-0.95 & $10 \%$ & $90 \%$ & 0.95 & 1.090 \\
\hline SGC-10-0.98 & $10 \%$ & $90 \%$ & 0.98 & 1.128 \\
\hline
\end{tabular}
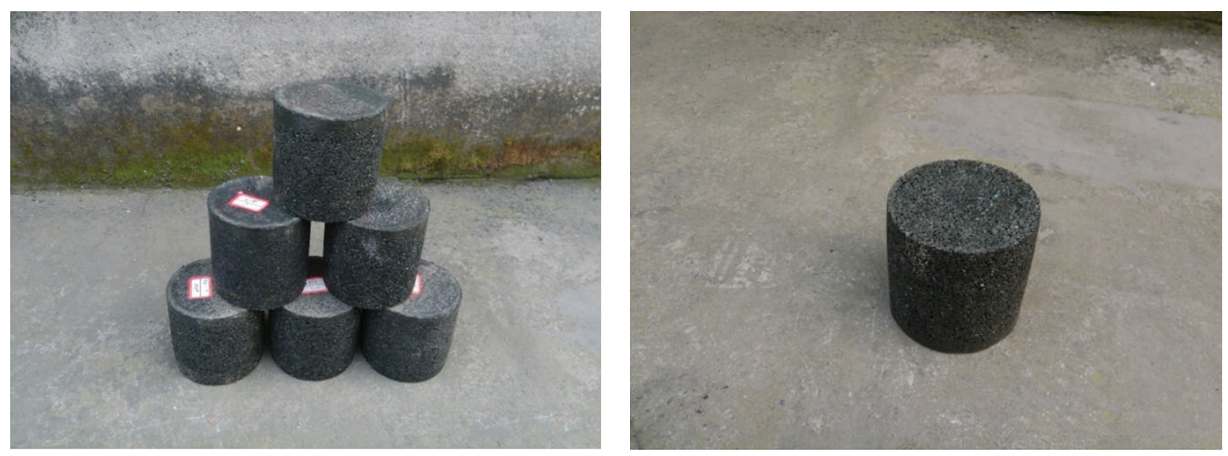

FIGURE 3: Specimens obtained from the end-of-life tires.

2.3. Preparation of the Specimens. In compliance with the guidelines presented by standard ISO3386-2-1997 [14] for the mechanical and energy absorption capabilities tests of these materials, all specimens had radii of $50 \mathrm{~mm}$ and heights of $100 \mathrm{~mm}$. However, large increases of the compressive section area of the specimens were found to occur during the pressure testing process as a result of their relatively large elasticity. Therefore, the radii of the specimens were increased from $50 \mathrm{~mm}$ to $100 \mathrm{~mm}$ to correspond to the size of the bearing pad. Figure 3 shows the specimens obtained from end-of-life tires.

2.4. Characteristics of the Track Section in Laboratory. As stated previously, this research was performed in the following three stages. The first stage focused on the design parameters of WTDCEs and their impact. The second stage investigated the fatigue resistance of the elements. Finally, the third stage focused on the effect of the use of the WTDCEs on railway track vibration decay rate and rail accelerance.

The compaction index used in this paper was calculated according to the following equation:

$$
\text { Compaction index }=\frac{D^{*}}{D_{s}},
$$

where $D^{*}$ is the apparent density of the WTDCEs formed by freely dropping the source materials into a mold, according to ISO $845-2006$ [15]. The relative density $\left(D_{s}\right)$ values of the waste-tires rubber materials are the densities of the specimens normalized to the density of the solid tire material $\left(D_{s}=\right.$ $\left.1.15 \mathrm{~g} / \mathrm{cm}^{3}\right)$.
The uniaxial compression tests were performed on cylindrical specimens $100 \mathrm{~mm}$ in radii and $100 \mathrm{~mm}$ in height using an LETRY WEW-600B electromechanical tester equipped with a $600 \mathrm{kN}$ load cell. The specimen was placed between two parallel steel platens, and the spherically aligned platens were coated with Vaseline to reduce friction with the compression specimens. Static mechanical properties tests were performed according to the ISO3386-2-1997 guidelines [14], which specify the load range values and the load method. For this study, a constant crosshead speed of $5 \mathrm{~mm} / \mathrm{min}$ was used for all tests, and the axle load was $4 \mathrm{kN}$.

The full-scale model used for laboratory measurements and the analysis of the accelerance of the grooved rail with the WTDCEs and standard grooved rail is presented below. The rail grid model was constructed with a concrete tracksupporting layer and two sets of support blocks and fastening systems: for one set, the rail was embedded by means of damping chamber elements, and for the other set, a standard grooved rail was used. For the testing of the acceleration admittance of the specimens, the method for measuring response to mechanical shock was used in accordance with ISO 7626-5 [16]. Mechanical shock was stimulated by an instrumented hammer in the vertical direction on the railhead, and the excitation point was placed at the midpoint of a sleeper bay, as shown in Figure 4(a). The response was measured by accelerometers at the vibration pick-up point, which was in close proximity to the excitation point, as shown in Figures 4(a) and 4(b). The measuring system consisted of a DHDAS-5920 PULSE modulator analyzer for recording the vibration parameters together with three LC0102 acceleration 


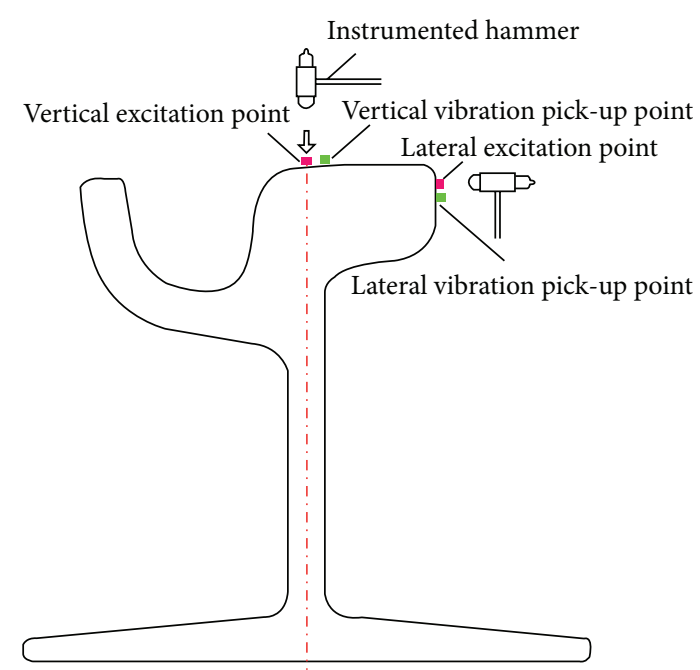

(a) Arrangement of the excitation point

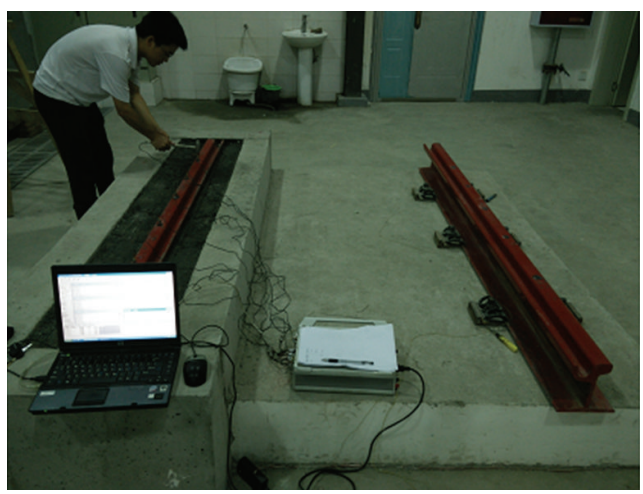

(c) System with WTDCEs

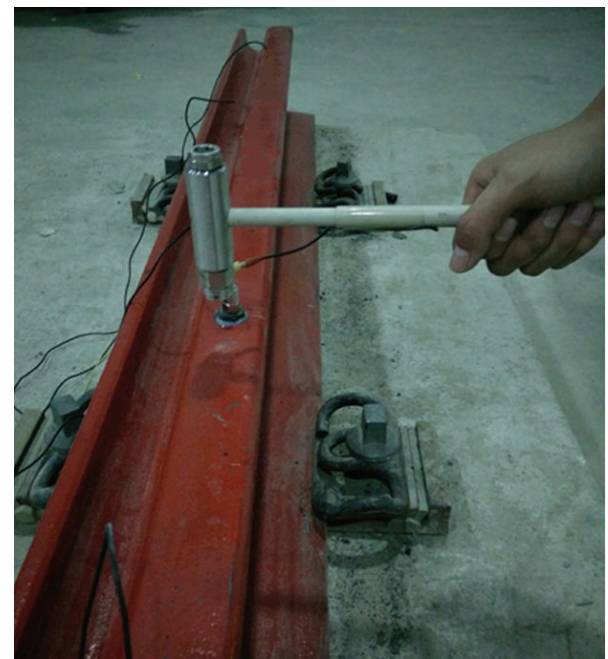

(b) Arrangement of the vibration pick-up points of the standard grooved rail

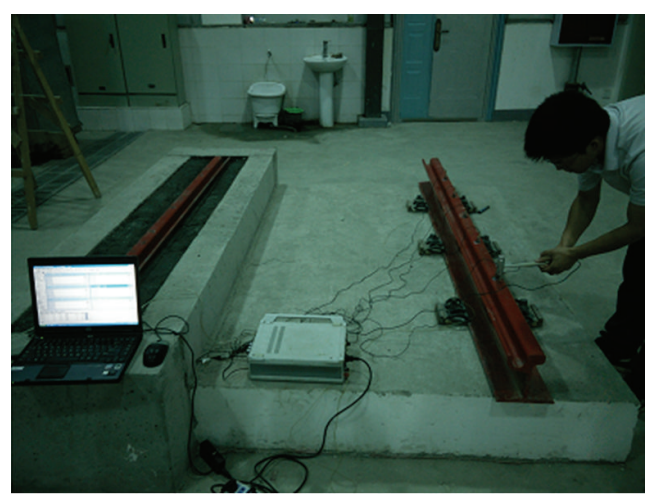

(d) System without WTDCEs

FIGURE 4: Modern tram track system with and without WTDCEs.

detectors and a LC1303 shock stimulation hammer. The accelerometers were mounted to the measured construction using epoxy resin adhesives.

The track vibration decay rates, which quantify the attenuation of rail vibration with distance along the track and have the strongest influence on the amount of noise radiated by the rail, were measured in the test section of Line One of the Guiyang light rail system and were compared with the track decay rates data obtained from the conventional adjacent section. The layout of the accelerometers and the implementation of the test are according to [14].

\section{Test Results and Discussion}

\subsection{Impact of the Design Parameters}

\subsubsection{Gradation Combination}

(1) Compression Behavior. Figure 5 shows the compressive stress-strain curves of WTDCEs for different gradation combinations but with the same compaction index. The figure shows that the mechanical behavior of WTDCEs is very similar to that of closed-pore foamed material due to the addition of polyurethane and the application of vulcanization craft [17]. Furthermore, from these curves, the stress and strain variation trends of WTDCEs in different gradation combinations were clearly similar, exhibiting two regions: linear elasticity at low stresses, followed by densification, where stress increased steeply and the stress growth with strain in the densification region was greater than that in the linear elasticity region. The value of the densification strain of the five specimens is $0.25,0.30,0.37,0.39$, and 0.40 , respectively. This behavior occurred because the internal pore walls of the material resisted the load when it was relatively small. The pores were crushed as the load increased. Simultaneously, the waste-tires particles resisted load instead of the internal pore walls.

From Figure 5, the value of the densification strain of WTDCEs becomes larger as the content of fine rubber particles decreases. The differences in the five compression stress-strain curves might be due to their different porosities. The porosity of the specimen increases as the content of fine rubber particles increases under the condition of a fixed compaction index. 


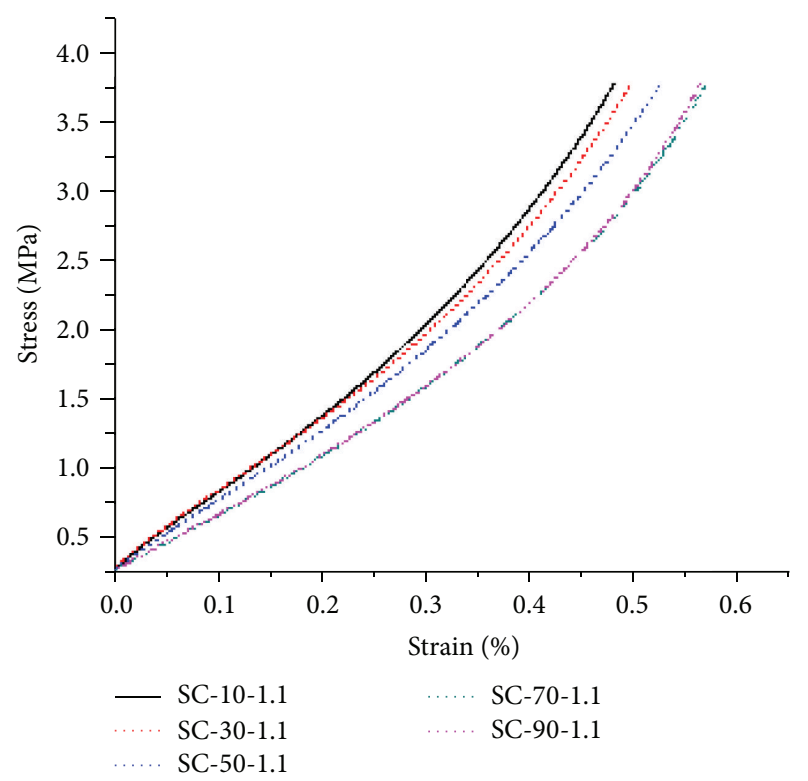

FIGURE 5: Compressive stress-strain curves for different gradation combinations.

(2) Energy Absorption Characteristics. The energy absorption characteristic, which can directly reflect the ability of a material to convert the work acting on the material to potential energy or heat energy during loading, is an important technological property of the WTDCEs. In this study, three parameters were utilized, that is, the energy absorption capacity, the energy absorption efficiency, and the ideality parameter.

The energy absorption capacity of WTDCEs can be obtained from the area under the stress-strain curve up to a certain strain [17], as follows:

$$
W=\int_{0}^{\varepsilon} \sigma d \varepsilon,
$$

where $\varepsilon$ and $\sigma$ are the compressive stress and strain, respectively.

Figure 6 shows the energy absorption capacity during compression loading as a function of the strain on the WTDCEs specimens for varying gradation combinations. As shown in the figure, on the one hand, the energy absorption capacity of all specimens increases with strain, and on the other hand, the energy absorption capacity decreases as the content of fine rubber particles increases at the same strain; moreover, the difference becomes larger as the strain increases. Figure 7 illustrates the energy absorption capacity as a function of the permitted compression stress of the specimens with varying contents of fine rubber particles. It can be concluded that the energy absorption capacity of WTDCEs rises with increasing stress. In addition, the value of this parameter increases with the increase of the content of fine rubber particles at a fixed stress. However, the magnitude of the increase is very small for a low permitted stress but relatively large for a high permitted stress.

Therefore, the energy absorption capabilities have a close relationship with the gradation combination of WTDCEs and

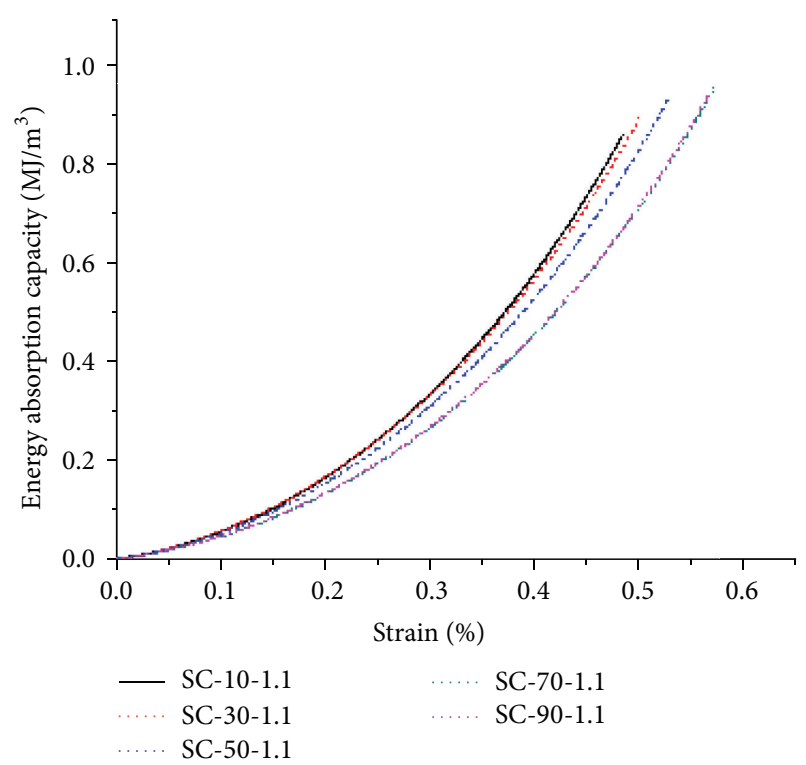

FIGURE 6: Energy absorption capacity of the WTDCEs.

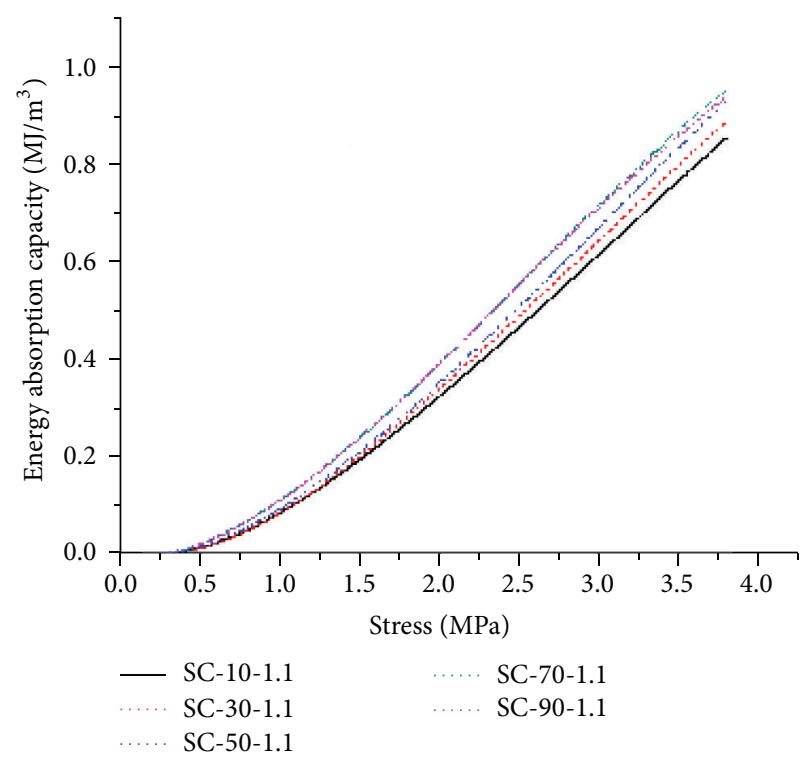

FIGURE 7: Energy absorption capacity of the WTDCEs.

the permitted strain and stress, and the effect of the WTDCEs gradation combination on the energy absorption capabilities is far more significant in the condition of a high permitted stress or strain than in the condition of a low permitted stress or strain.

Another parameter that characterizes the energy absorption of WTDCEs is the energy absorption efficiency, $E$, which is the ratio of the real energy absorbed to the ideal energy absorbed for a given strain, $\varepsilon$, and the corresponding peak stress, $\sigma_{p}$, and can be calculated using the following equation [17]:

$$
E=\frac{\int_{0}^{\varepsilon} \sigma d \varepsilon}{\sigma_{p} \cdot \varepsilon} .
$$




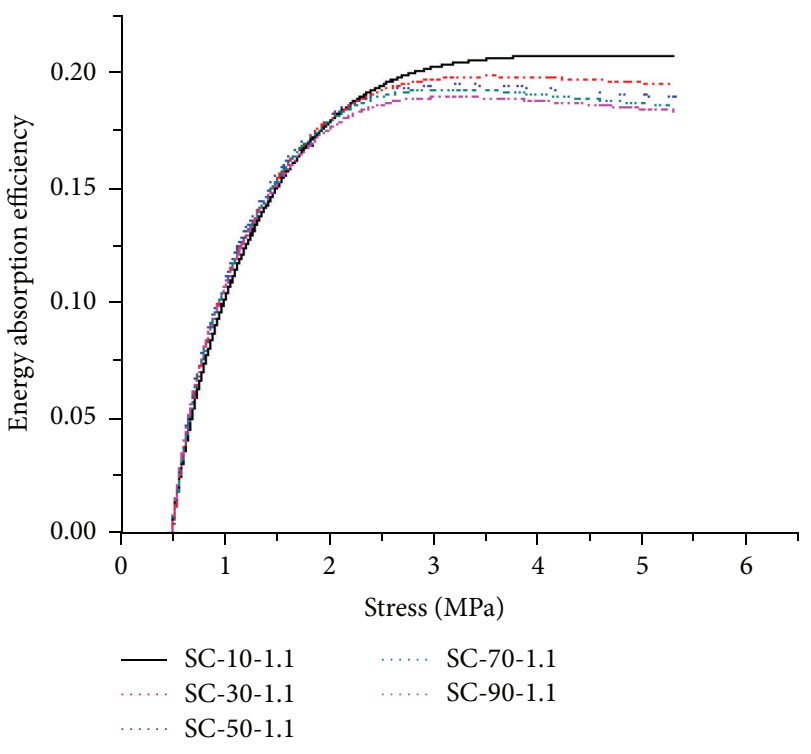

FIGURE 8: Energy absorption efficiency of the WTDCEs.

Figure 8 shows the efficiency of energy absorption efficiency as a function of stress of specimens with varied gradation combinations. As shown from the figure, the energy absorption efficiency reaches a maximum value for each specimen, but the maximum value is attained at different stress values for the different WTDCEs specimens. Furthermore, the stresses that correspond to the maximum values are all between $2.5 \mathrm{MPa}$ and $3 \mathrm{MPa}$. The energy absorption efficiency value decreases slowly after the maximum value due to the application of polyurethane and the high density of WTDCEs. In addition, with decreasing content of fine rubber particles, the maximum value is found to appear at a lower stress; additionally, the apex of the efficiency curves becomes sharp, and the range of peak becomes narrower.

The last parameter used in this study to characterize the energy absorption of WTDCEs is the ideality parameter, $I$, which is defined as the ratio between the energy absorbed by an actual and an ideal cushioning material compressed to the same strain [17], defined as follows:

$$
I=\frac{\int_{0}^{\varepsilon_{p}} \sigma d \varepsilon}{\sigma_{p} \cdot \varepsilon_{p}},
$$

where $\varepsilon_{p}$ is the corresponding peak strain.

Figure 9 shows the ideality of the studied WTDCEs as a function of stress. It is obvious that the ideality of the WTDCEs decreases with increasing stress. Furthermore, the value of this parameter decreases with increasing fine rubber particle content at fixed stress; that is, the specimen with a fine rubber particle content of $10 \%$ provides the best gradation combination among the WTDCEs from the perspective of improving the work efficiency of an actual modern track system in energy absorption.

In consideration of the fact that the actual lateral stress of the WTDCEs is approximately 2.4 MPa [18], the results above suggest that the optimal gradation combination of WTDCEs

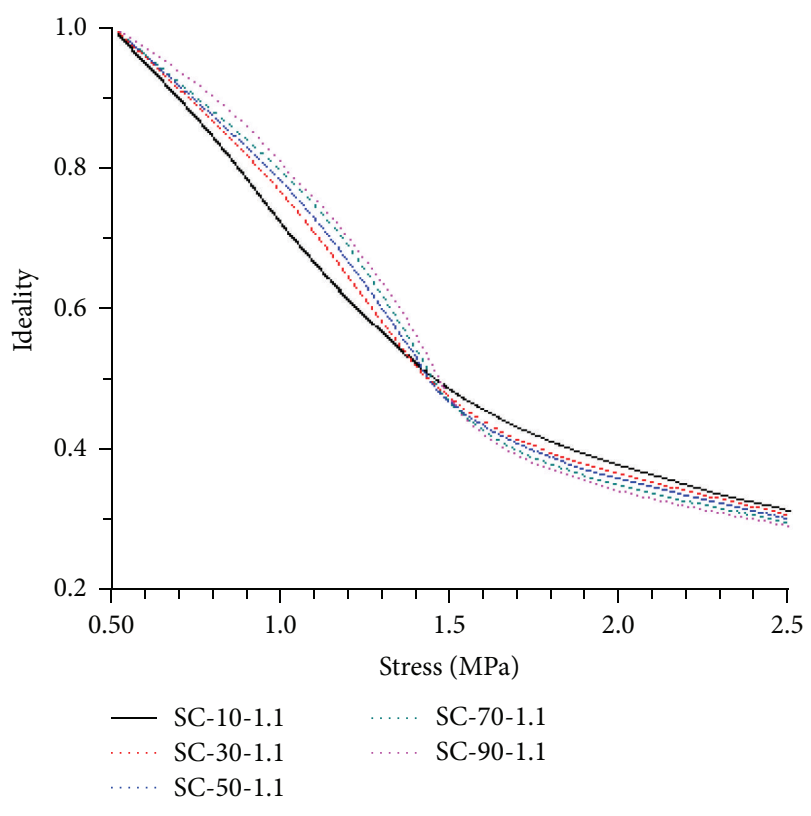

FIGURE 9: Ideality of the WTDCEs.

is as follows: the content of fine rubber particles is $10 \%$ and the content of coarse granules is $90 \%$.

3.1.2. Compaction Index. To further maximize the energy absorption of the materials, laboratory tests were performed on four gradations of compaction index, namely, 0.88, 0.92, 0.95 , and 0.98 .

(1) Compression Behavior. Figure 10 represents the relationship between the stress and strain of WTDCEs specimens with different compaction indices. Similar to Figure 5, Figure 10 also shows that the stress-strain responses of all the curves exhibit the typical behavior of a closed-pore foamed material. In addition, the stress-strain curves are characterized by typical characteristics of two distinct regions. The stress linearly increases with increasing strain up to a strain of approximately 0.15 , and no yield point is observed in these curves. The stress level of the WTDCEs is very low (approximately 1.0 MPa) down to a strain of 0.15 and is approximately $4.5 \mathrm{MPa}$ to a strain of $50 \%$.

The stress-strain relations of WTDCEs specimens with varied compaction indices are complicated. The required stress of the specimen with a compaction index of 0.98 is observed to always be greater than that of any other specimens for a specific strain. However, when the compaction index is less than 0.98 , there is an intersection point among the curves. Moreover, before the strain exceeds the abscissa value of the inflection point, the stress required for a given strain increases slightly with increasing compaction index, while the change is more significant after the strain exceeds this abscissa value. This behavior might occur because deconstructed waste-tires particles and air pockets inside the pore cells bear the applied loads in common for the WTDCEs. In general, the densification strain of the specimen increases 


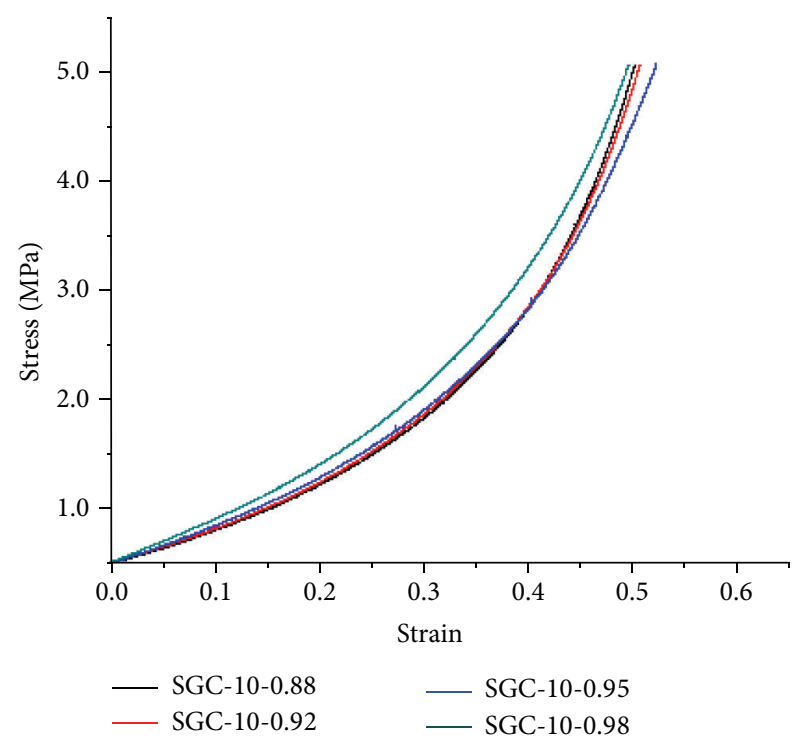

FIGURE 10: Compressive stress-strain curves at different compaction indices.

with increasing compaction index. During compression, for a particular specimen, when the strain exceeds its densification strain, densification occurs as a result of the collapse of the pore walls; thus, only deconstructed waste-tires particles bear the applied loads.

To the best of the authors' knowledge, there is no accurate mechanical model for this type of material. Although the deformation mechanism remains unclear, the deformation behavior of the WTDCEs material can be interpreted partially according to existing explanations for the deformation mechanism of closed-pore foamed material and the properties of the compounded rubber. In the early stage of compression, the elastic deformation of WTDCEs proceeds mainly by the squeezing of the air inside the pore cell and bending, which do not result in a notable reduction in the volume of the WTDCEs cell. Damping due to air inside the pores would dissipate some energy at this stage.

As the stress increases, some of the pore walls collapse, and the volume of the WTDCEs cell also partially decreases by squeezing some of the air out of the pores. At this time, the deformation of the WTDCEs stems from squeezing and bending behaviors of air inside the pore cell and compressing actions of deconstructed waste-tires particles. The corresponding compression modulus of the WTDCEs is larger than that of the early stage. With a further increase of stress, all the pore walls become compressed; as a result, the wastetires particles become the only bearing body for the applied force, and the compression modulus of WTDCEs further becomes larger.

(2) Energy Absorption Characteristics. Figure 11 represents the energy absorption capability of WTDCEs as a function of strain at different compaction indices, which is calculated according to (2). Figure 11 shows that the energy absorption capability of WTDCEs increases approximately exponentially with increasing strain. Furthermore, for a given strain,

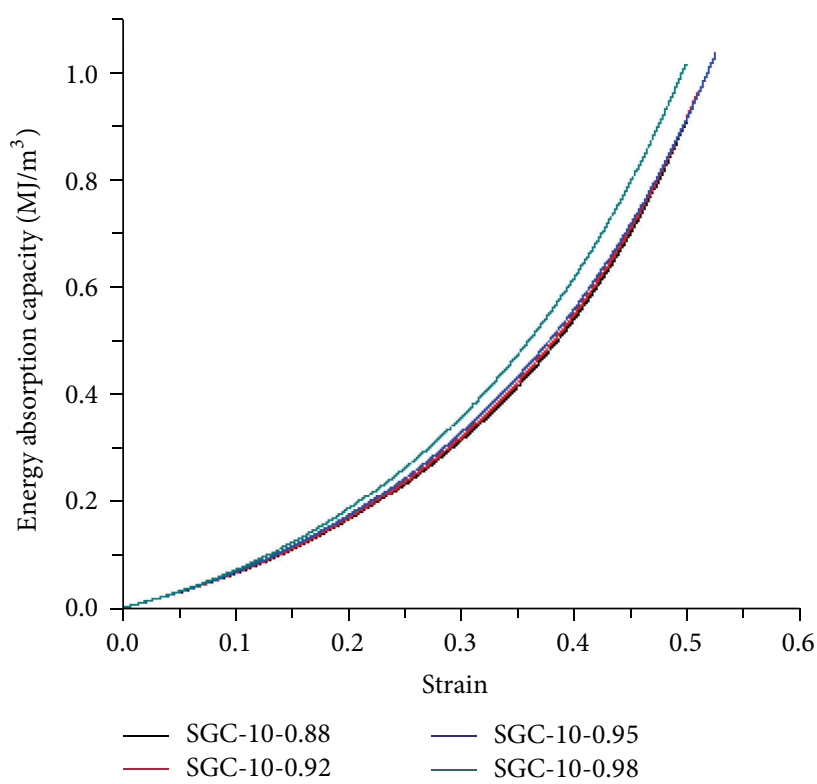

FIGURE 11: Energy absorption capacity of the WTDCEs.

the energy absorption capability per unit volume of the WTDCEs increases with the compaction index, and the energy absorption capability increase is most remarkable when the compaction index of the WTDCEs reaches 0.98 . Accordingly, it can be inferred that energy absorption capability of WTDCEs increases with compaction index under certain strain, and when the compaction index is 0.98 , the energy absorption capability of WTDCEs is much larger than that of other specimens, especially above the strain of 0.2 .

Figure 12 clarifies the energy absorption capacity as a function of permitted compression stress of specimens with varied compaction indices of the WTDCEs. It can be deduced that the energy absorption capacity of WTDCEs decreases with increasing compaction index at a certain stress in the case of low stress. However, the energy absorption capacity of WTDCEs increases with increasing compaction index in the case of high stress at a fixed stress. In addition, for a given stress of 2.4 MPa, the specimen with the highest compaction index has the greatest energy absorption capacity.

Examining Figures 11 and 12, it can be concluded that, over a particular stress range, increasing the compaction index of WTDCEs is helpful to improve the energy absorption capacity of WTDCEs at a certain gradation combination. This result occurs because increasing the compaction index enhances the cross-linking actions among the waste-tires particles in the process of vulcanization.

The energy absorption efficiency-strain curves of the WTDCEs specimens with varied compaction indices are calculated from (3) and shown in Figure 13. As exhibited from the figure, the energy absorption efficiency increases with increasing stress. In addition, the energy absorption capacity of the WTDCEs rises with increasing compaction index over the stress range from $0.5 \mathrm{MPa}$ to $2.1 \mathrm{MPa}$; however, the energy absorption capacity of the WTDCEs decreases with increasing compaction index in the stress range from $2.1 \mathrm{MPa}$ 


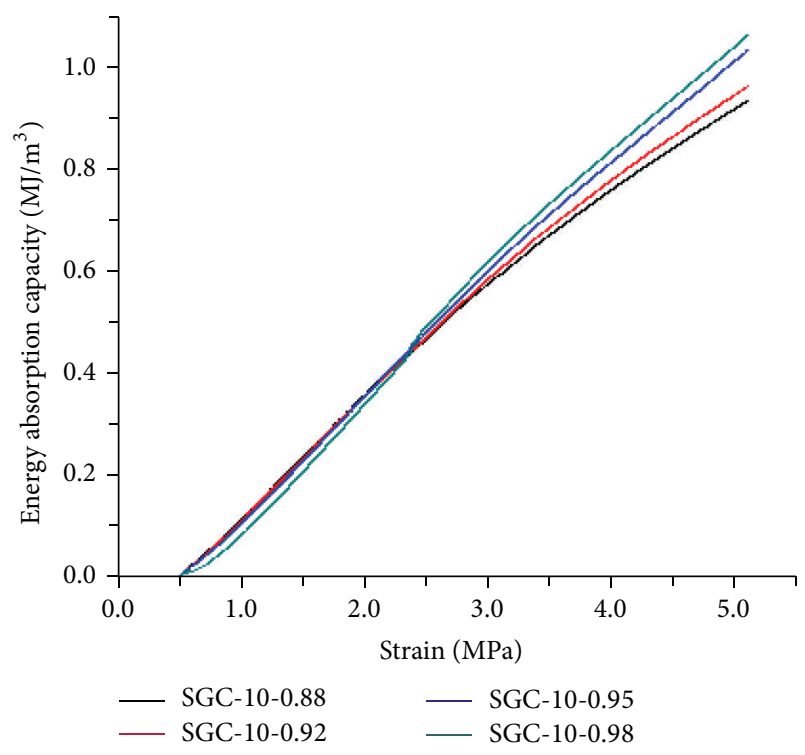

FIGURE 12: Energy absorption capacity of the WTDCEs.

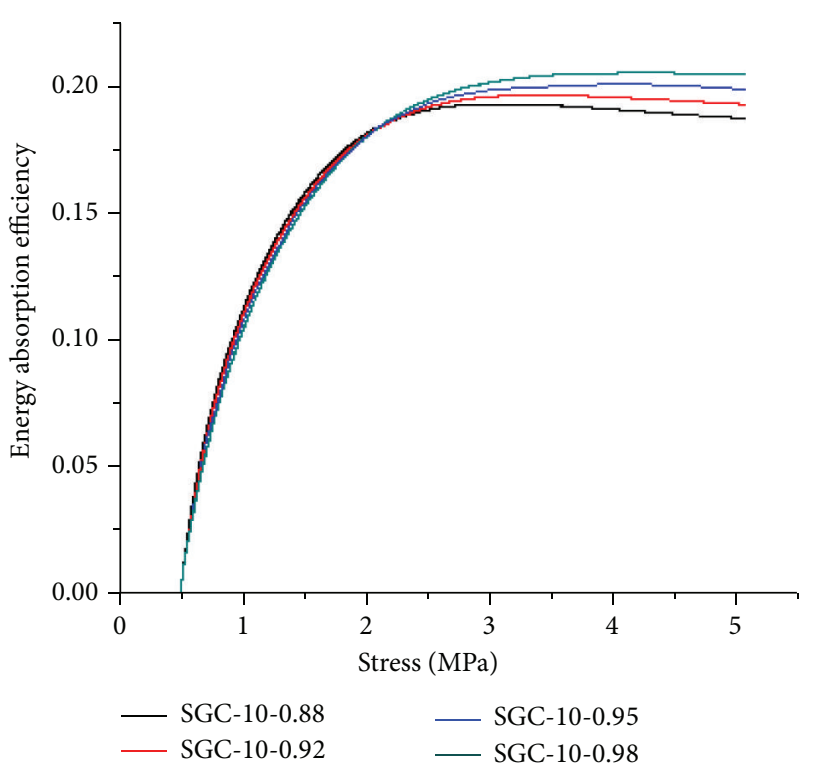

FIGURE 13: Energy absorption efficiency of the WTDCEs.

to 5.0 MPa. Additionally, the energy absorption efficiency passes through a maximum value, but the maximum value is attained at different stress values for different WTDCEs specimens with different compaction indices. The maximum values of the WTDCEs specimens with compaction indices of $0.98,0.95,0.92$, and 0.88 are $0.205,0.200,0.195$, and 0.190 , respectively.

Figure 14 shows the ideality of the studied WTDCEs specimens as a function of stress. It is clear that the ideality of the WTDCEs declines with increasing stress. Furthermore, the relationship between the ideality and the compaction index of a WTDCEs specimen is found to be complicated; however, the ideality of WTDCEs increases with increasing compaction index at a fixed stress in stress range of 2.0 MPa to

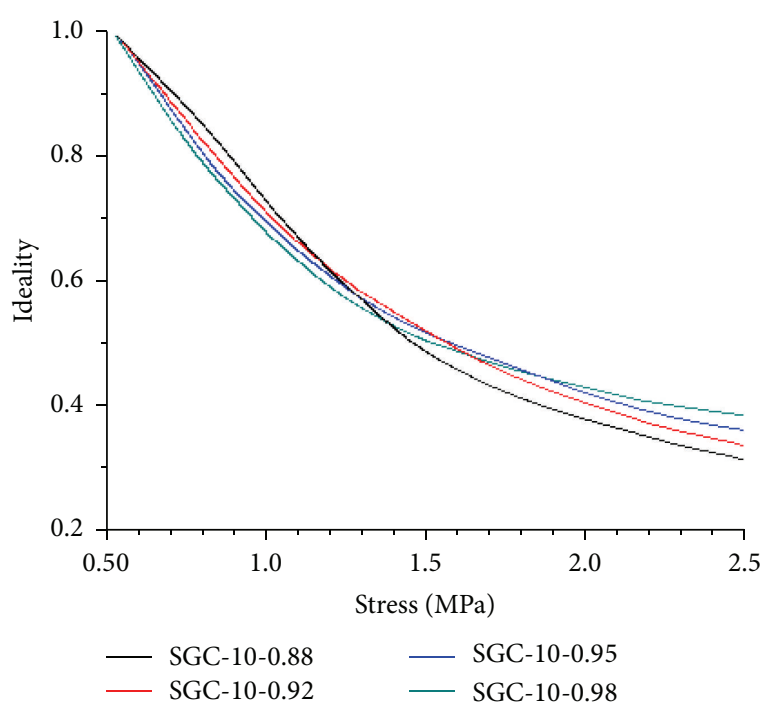

FIGURE 14: Ideality of the WTDCEs.

2.5 MPa. In conclusion, because the actual lateral stress of the WTDCEs is approximately $2.4 \mathrm{MPa}$, the results above suggest that the optimal compaction index of WTDCEs is 0.98 .

3.2. Vibration Damping Effect of WTDCEs on the Track Response in the Laboratory. A comparison of the vertical and lateral accelerance amplitude of the rail head between a standard grooved rail and a rail with damping chamber elements is shown in Figures 15(a) and 15(b), respectively. These results clearly demonstrate in the frequency domain that the vibration of the rail head is significantly reduced after the application of the damping chamber elements. In the preceding graph, a general decrease of the vertical accelerance amplitude of the rail with damping chamber elements relative to the standard grooved rail is clearly observed in the frequency range of $0-4000 \mathrm{~Hz}$, as the maximum acceleration reading decreases from $0.195 \mathrm{~m} \cdot \mathrm{s}^{-2} / \mathrm{N}$ to $0.103 \mathrm{~m} \cdot \mathrm{s}^{-2} / \mathrm{N}$. Meanwhile, from the following graph, the lateral accelerance amplitude of the rail with damping chamber elements is far less than that of the standard grooved rail in the low frequency range of $0-200 \mathrm{~Hz}$ and the middle frequency range of $200-$ $1000 \mathrm{~Hz}$. This result indicates that the lateral vibration of the rail head at frequencies of $0-1000 \mathrm{~Hz}$ can be significantly attenuated by the damping chamber elements. In addition, the figure shows that, in comparison with the standard rail, the lateral accelerance amplitude of the rail with damping chamber elements decreases dramatically in most parts of the high frequency range between $1000 \mathrm{~Hz}$ and $4000 \mathrm{~Hz}$.

In conclusion, it was possible to obtain significant reductions in the vertical and lateral vibration levels of the rail head in the frequency range of $0-4000 \mathrm{~Hz}$ by applying damping chamber elements, thereby achieving great reduction in the noise level radiated by the rail.

3.3. Vibration Damping Effect of WTDCEs on the Track Response In Situ. The main parameter with the strongest influence on the medium-high frequency vibration of 


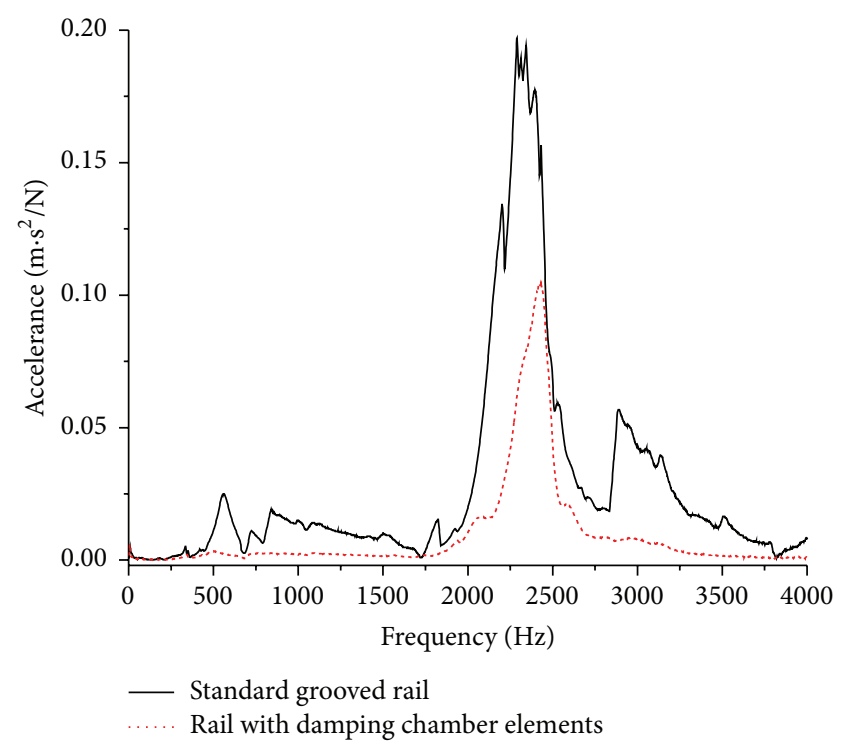

(a) Vertical accelerance of the rail head

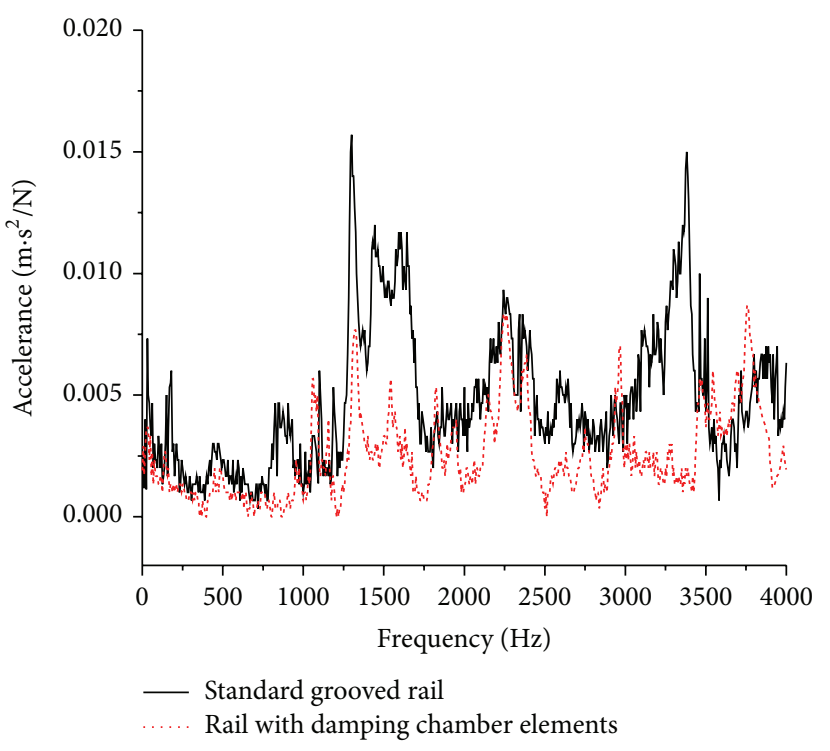

(b) Lateral accelerance of the rail head

FIGURE 15: Accelerance of the rail head.

the rail and the amount of noise radiated by the rail is the rate of decay of vibration in the vertical direction along the rail, usually expressed in $\mathrm{dB} / \mathrm{m}[6]$. In this research, the measured vertical decay rates of the track with a standard grooved rail and the track with a standard grooved rail surrounded by damping chamber elements are shown in Figure 16, which were obtained according to the test method described in [13]. Figure 16 shows that, for the standard grooved rail, the decay rate is between $5 \mathrm{~dB} / \mathrm{m}$ and $11 \mathrm{~dB} / \mathrm{m}$ at low frequency range of $0-200 \mathrm{~Hz}$. In addition, the decay rate reaches a peak $18 \mathrm{~dB} / \mathrm{m}$ at approximately $250 \mathrm{~Hz}$. At high frequencies above $1000 \mathrm{~Hz}$, the decay rate is lower than $2 \mathrm{~dB} / \mathrm{m}$. However, when the damping chamber elements are used, the vertical decay rate of rail vibration is significantly increased in the frequency range of $200-10000 \mathrm{~Hz}$; in particular, at the middle frequencies in the range of $200-1000 \mathrm{~Hz}$, the increase is notable, with a maximum increase of $10 \mathrm{~dB} / \mathrm{m}$ at approximately $250 \mathrm{~Hz}$. Therefore, the rail vibration energy can effectively be reduced in that frequency region. This result is advantageous to elimination of the rolling noise because the rail component of noise is dominant in that frequency region.

In view of the above information, one can confidently conclude that it is very effective to use the damping chamber elements made from waste tires to control the rail vibration and noise of a modern tram track system.

\section{Conclusions}

The aim of this work was to study the feasibility of using damping chamber elements manufactured from deconstructed waste tires to be applied as vibration and noise control elements in a modern tram track system. These damping chamber elements are produced by first grinding

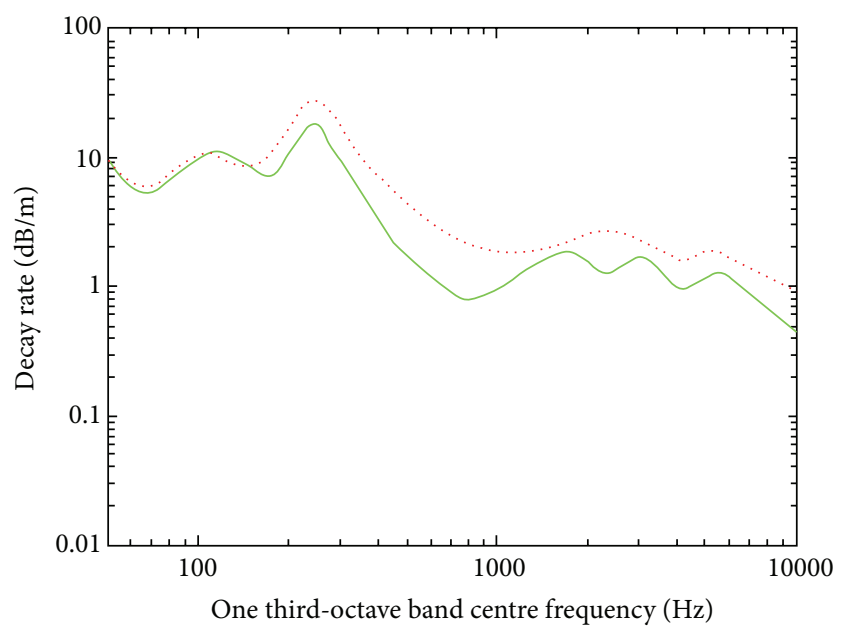

FIGURE 16: Measured track decay rates: standard grooved rail (green line) and rail with damping chamber elements (red line).

end-of-life tires and then mixing the deconstructed wastetires particles with carbon black and polyurethane, followed by vulcanizing the mixtures. The research was conducted in 3 stages: (i) study of the influence of the design parameters of the damping chamber elements (gradation combination and compaction index) on their compression-test performance; (ii) determination of the vibration damping performance of damping chamber elements using a test of the dynamic characteristics of rail accelerance; and (iii) a comparative study of the vibration decay rate between a track with standard grooved rails and a track with rails surrounded by damping chamber elements in modern tram lines in the field. On the basis of the results obtained from the different 
work phases in this study, the following conclusions can be extracted.

(a) WTDCEs that contain 10\% fine rubber particles and $90 \%$ coarse granules provided the best energy absorption characteristics under conditions where the stress was approximately $2.4 \mathrm{MPa}$, making them the most appropriate for use in a modern tram system. In addition, for the same stress case, the optimal compaction index of WTDCEs was 0.98 due to the greater compaction index, which enhanced the crosslinking actions among the waste-tires particles in the process of vulcanization, thereby enabling improved energy absorption properties.

(b) Based on the laboratory compression-test results, the optimal design parameters were used to manufacture damping chamber elements that were applied to a full-scale modern track model in the laboratory. From the results, significant reductions in the vertical and lateral vibration levels of rail head in the frequency range of $0-4000 \mathrm{~Hz}$ were obtained by applying WTDCEs. This result is quite significant because, in that frequency region, the rail structure noise component is dominant in the rolling noise of a tram.

(c) During the field study, a significant increase in the amplitude of the rail vertical vibration decay rate was found in the frequency range of $200-10000 \mathrm{~Hz}$, especially in the middle frequencies between 200 and $1000 \mathrm{~Hz}$. As a result, the rail vibration energy could be effectively reduced in that frequency region by the use of WTDCEs. This result is advantageous to the elimination of rolling noise because the rail component is dominant in that frequency region.

In summary, in this study, damping chamber elements manufactured from deconstructed tires may be suitable for use in controlling rail vibration and noise in a modern tram track system.

\section{Disclaimer}

The results and opinions presented are those of the authors and do not necessarily reflect those of the sponsoring agencies.

\section{Conflict of Interests}

The authors declare that there is no conflict of interests regarding the publication of this paper.

\section{Acknowledgment}

This research is sponsored by the National Natural Science Foundation of China, no. U1234201 and no. 51425804. This support is gratefully acknowledged.

\section{References}

[1] X. L. Zhuang, Y. I. Wang, H. He et al., "Haze insights and mitigation in China: an overview," Journal of Environmental Sciences, vol. 26, no. 1, pp. 2-12, 2014.

[2] M. A. Pallas, J. Lelong, and R. Chatagnon, "Characterisation of tram noise emission and contribution of the noise sources," Applied Acoustics, vol. 72, no. 7, pp. 437-450, 2011.

[3] G. Kouroussis, N. Pauwels, P. Brux, C. Conti, and O. Verlinden, "A numerical analysis of the influence of tram characteristics and rail profile on railway traffic ground-borne noise and vibration in the Brussels Region," Science of the Total Environment, vol. 482-483, no. 1, pp. 452-460, 2014.

[4] A. Jolibois, D. Duhamel, V. W. Sparrow, J. Defrance, and P. Jean, "Scattering by a cylinder covered with an arbitrary distribution of impedance and application to the optimization of a tramway noise abatement system," Journal of Sound and Vibration, vol. 331, no. 25, pp. 5597-5622, 2012.

[5] J. Mandula, B. Salaiová, and M. Koval'aková, "Prediction of noise from trams," Applied Acoustics, vol. 63, no. 4, pp. 373-389, 2002.

[6] C. J. C. Jones, D. J. Thompson, and R. J. Diehl, “The use of decay rates to analyse the performance of railway track in rolling noise generation," Journal of Sound and Vibration, vol. 293, no. 3-5, pp. 485-495, 2006.

[7] J. Maes and H. Sol, "A double tuned rail damper-increased damping at the two first pinned-pinned frequencies," Journal of Sound and Vibration, vol. 267, no. 3, pp. 721-737, 2003.

[8] X. J. Yin, "Theoretical and experimental study on the labyrinth constrained damping layer," Noise and Vibration Control, vol. 58, pp. 148-152, 2007.

[9] D. J. Thompson, C. J. C. Jones, T. P. Waters, and D. Farrington, "A tuned damping device for reducing noise from railway track," Applied Acoustics, vol. 68, no. 1, pp. 43-57, 2007.

[10] F. Ltourneaux, F. Margiocchi, and F. Poisson, "Complete assessment of rail absorber performances on an operated track in France," in Proceedings of the World Congress on Railway Research, CDROM, Montreal, Canada, 2006.

[11] M. Sol-Sánchez, F. Moreno-Navarro, and M. C. Rubio-Gámez, "Viability of using end-of-life tire pads as under sleeper pads in railway," Construction and Building Materials, vol. 64, pp. 150156, 2014.

[12] M. Bravo and J. de Brito, "Concrete made with used tyre aggregate: durability-related performance," Journal of Cleaner Production, vol. 25, pp. 42-50, 2012.

[13] J. Ryue, D. J. Thompson, P. R. White, and D. R. Thompson, "Decay rates of propagating waves in railway tracks at high frequencies," Journal of Sound and Vibration, vol. 320, no. 4-5, pp. 955-976, 2009.

[14] International Organization for Standardization, "Flexible cellular polymeric materials-determination of stress-strain characteristics in compression-part 2: high-density materials," ISO 3386-2, ISO, London, UK, 1997.

[15] International Organization for Standardization, "Cellular plastics and rubbers-determination of apparent density," ISO 845, ISO, Berlin, Germany, 2006.

[16] International Organization for Standardization, "Vibration and shock-experimental determination of mechanical mobilitypart 5: measurements using impact excitation with an exciter which is not attached to the structure," ISO 7626-5, ISO, Geneva, Switzerland, 1994. 
[17] S. Yu, J. Liu, M. Wei, Y. Luo, X. Zhu, and Y. Liu, "Compressive property and energy absorption characteristic of open-cell ZA22 foams," Materials and Design, vol. 30, no. 1, pp. 87-90, 2009.

[18] Chinese Standardization for Railway Organization, "GB/T 7928: general technical specifications for metro vehicles," Tech. Rep. GB/T 7928, Chinese Standardization for Railway Organization, Beijing, China, 2003. 

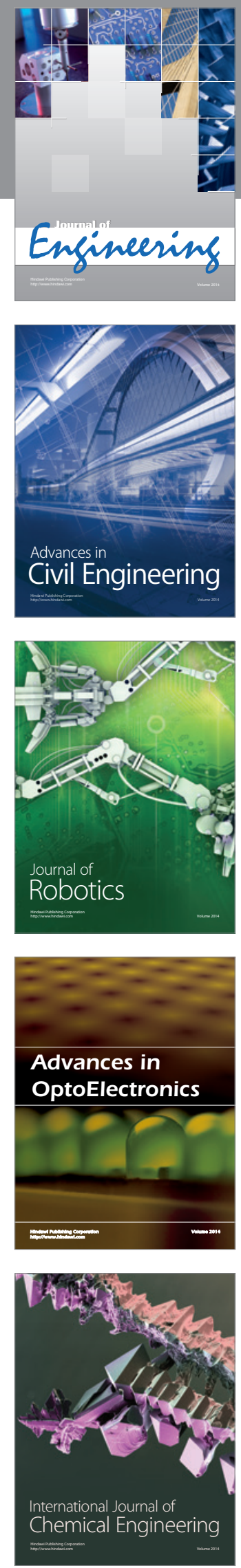

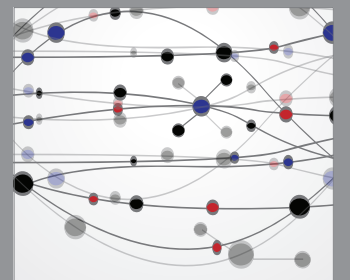

The Scientific World Journal
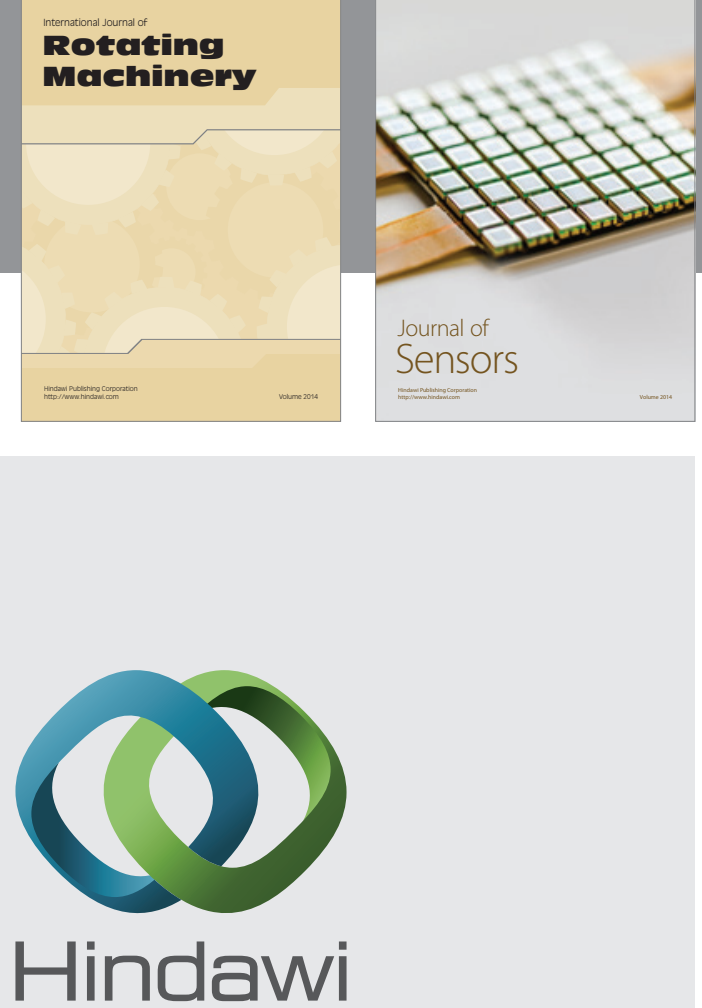

Submit your manuscripts at http://www.hindawi.com
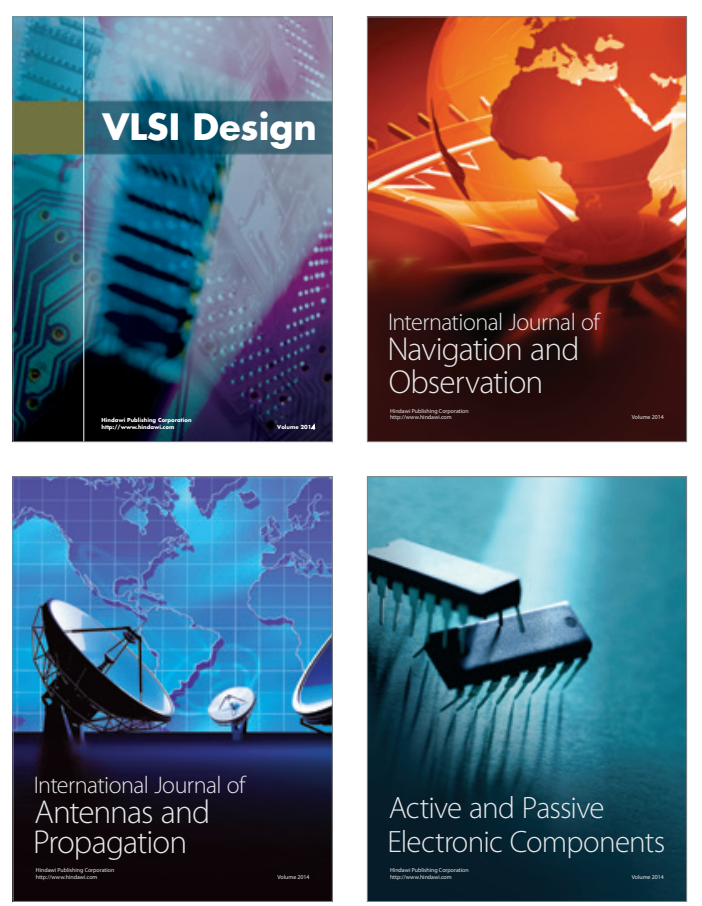
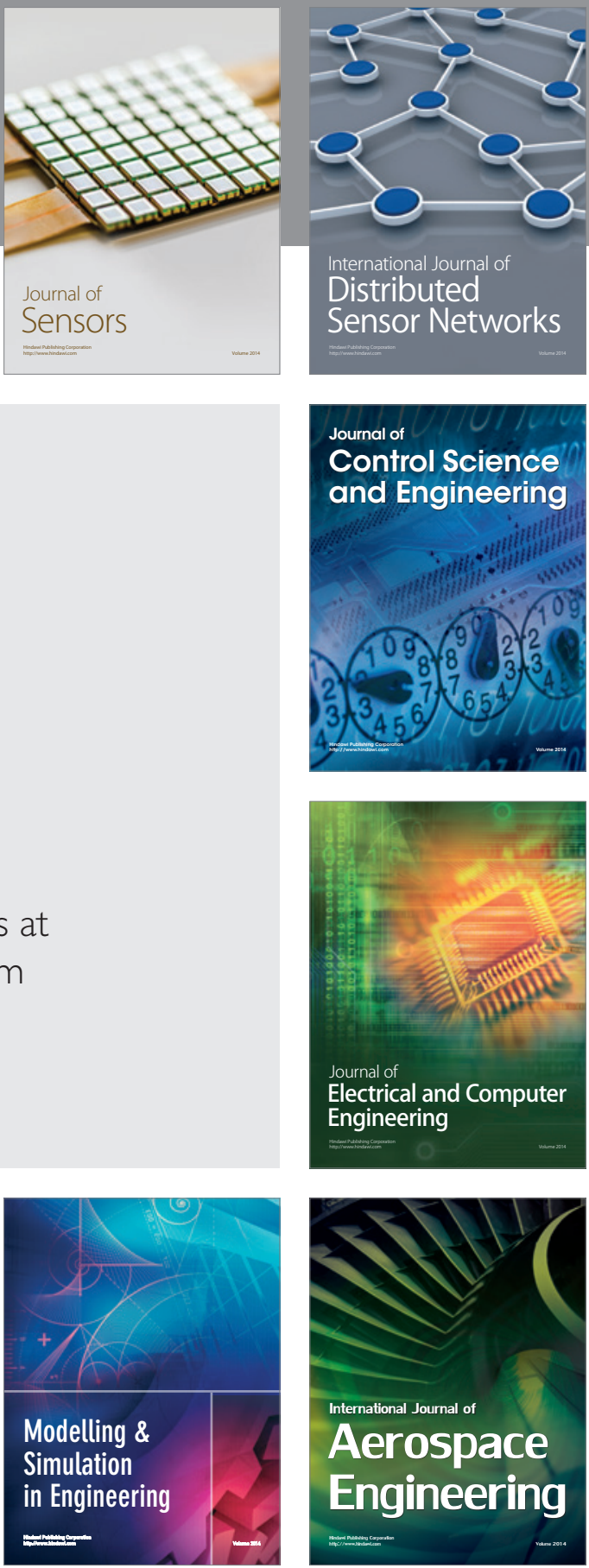

Journal of

Control Science

and Engineering
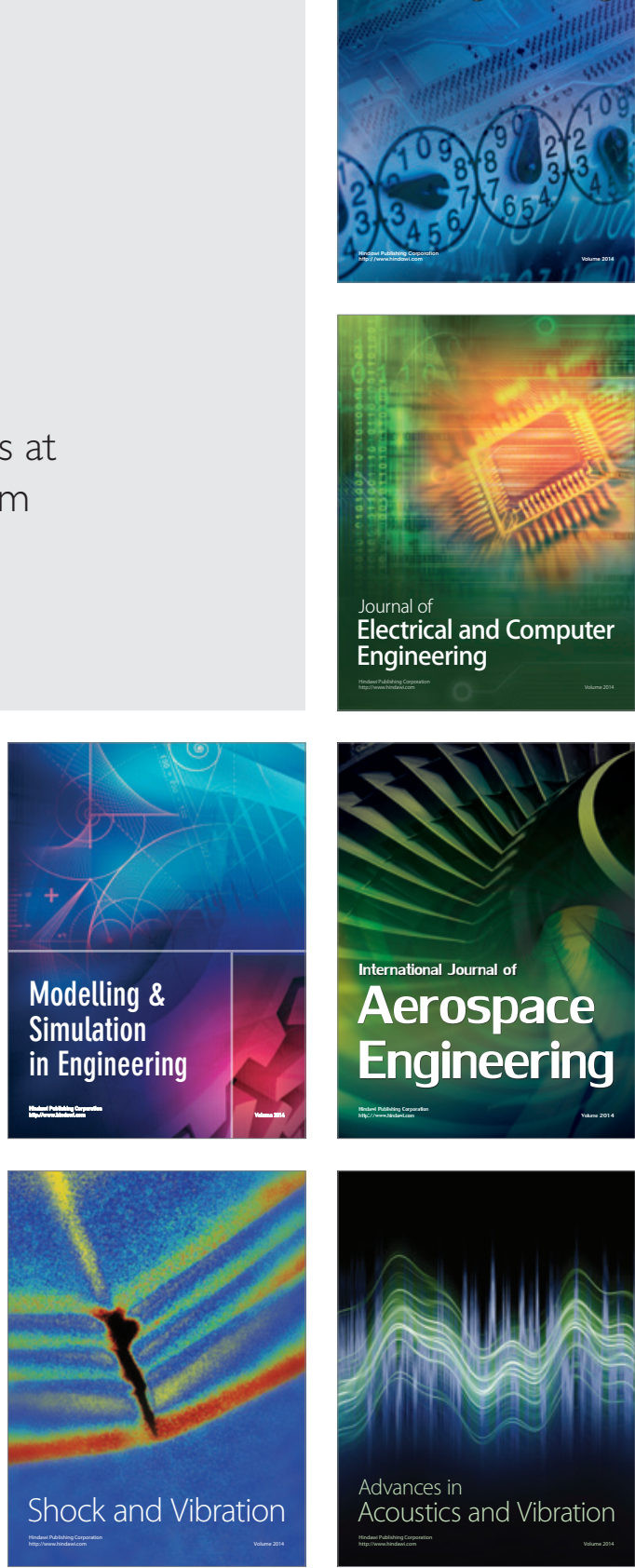